\title{
THE FORESHOCK ACTIVITY OF THE 1971 SAN FERNANDO EARTHQUAKE, CALIFORNIA
}

\author{
By Mizuho Ishida and Hiroo Kanamori
}

\begin{abstract}
All of the earthquakes which occurred in the epicentral area of the 1971 San Fernando earthquake during the period from 1960 to 1970 were relocated by using the master-event method. Five events from 1969 to 1970 are located within a small area around the main shock epicenter. This cluster of activity is clearly separated spatially from the activity in the surrounding area, so these five events are considered foreshocks. The wave forms of these foreshocks recorded at Pasadena are, without exception, very complex, yet they are remarkably similar from event to event. The events which occurred in the same area prior to 1969 have less complex wave forms with a greater variation among them. The complexity is most likely the effect of the propagation path. A well located aftershock which occurred in the immediate vicinity of the main shock of the San Fernando earthquake has a wave form similar to that of the foreshocks, which suggests that the foreshocks are also located very close to the main shock. This complexity is probably caused by a structural heterogeneity in the fault zone near the hypocenter. The seismic rays from the foreshocks in the inferred heterogeneous zone are interpreted as multiple-reflected near the source region which yielded the complex wave form. The mechanisms of the five foreshocks are similar to each other but different from either the main shock or the aftershocks, suggesting that the foreshocks originated from a small area of stress concentration where the stress field is locally distorted from the regional field. The number of small events with $S-P$ times between 3.8 to $6 \mathrm{sec}$ recorded at Mt. Wilson each month suggests only a slight increase in activity of small earthquakes near the epicentral area during the 2-month period immediately before the main shock. However, because of our inability to locate these events, the evidence is not definitive. Since the change in the wave forms is definite the present result suggests that detailed analyses of wave forms, spectra, and mechanism can provide a powerful diagnostic method for identifying a foreshock sequence.
\end{abstract}

\section{INTRODUCTION}

Foreshock activity has long been considered to be potentially useful for earthquake prediction. In fact, pronounced foreshock activity was one of the key elements in the successful short-term prediction of the 1975 Haicheng, China earthquake (e.g., Haicheng Earthquake Study Delegation, 1977). However, not all earthquakes are preceded by observable foreshock activity. Although Jones and Molnar (1976) found that 44 per cent of all large shallow events in the world from 1950 to 1973 had foreshocks, most large California earthquakes did not have pronounced foreshock activity.

In particular, the 1971 San Fernando earthquake was believed to be completely lacking in foreshocks. However, a recent study by Ishida and Kanamori (1977) suggested an increase in seismic activity near the hypocentral area of the $1971 \mathrm{San}$ Fernando earthquake for the 2-year period just before the main shock. Although this activity can be considered to be foreshock activity in a broad sense, the conclusion was solely based on the spatiotemporal plot of the epicenters; it was not clear whether this activity was physically distinct from the background activity. 
From the point of view of earthquake prediction, it is important to distinguish foreshock activity from swarm activity or ordinary background activity on a physical basis. To this end we made a more detailed study of the "foreshocks" of the San Fernando earthquake: (1) by relocating the events using the master-event method, (2) by studying the wave forms of these events recorded at Pasadena, (3) by investigating the mechanism, and (4) by examining the activity of smaller events.

Ishida and Kanamori (1977) identified five events located within $15 \mathrm{~km}$ from the epicenter of the San Fernando earthquake during the period from January 1969 to February 9, 1971. Whether these events can be called foreshocks or not may be somewhat controversial. Although there is no established definition of foreshocks, usually foreshocks refer to an activity preceding the main shock by hours or days. The activity before the San Fernando earthquake does not belong to this category. However, as we will show later, since these events are clearly distinct in several important aspects from the events prior to 1965 , in this paper we will call these events foreshocks.

\section{Relocation of HyPocenters}

All the events that occurred within $35 \mathrm{~km}$ from the epicenter of the San Fernando earthquake during the period from 1960 to 1971 were relocated by using the master event method (Johnson and Hadley, 1976). The master event employed is one of the best-constrained aftershocks used by Hadley and Kanamori (1978). The HYPO 71 location program (Lee and Lahr, 1975) were used, and the $S-P$ times at stations within about $100 \mathrm{~km}$ from the epicenter were included in the analysis. The $P$ times registered on the original card file at the Seismological Laboratory and the crustal structure employed by Hadley and Kanamori (1978) were used. Figure 1 shows the results for the three periods: period II (1961 to 1964), period III (1965 to 1968), and period IV (1969 to February 9, 1971). The events during period I (1932 to 1960) are taken from the Caltech Catalog (Hileman et al., 1973) without relocation. These periods are the same as in Ishida and Kanamori (1977). The overall pattern is the same as that found in the previous paper: a relatively high activity during period II, complete absence of activity within $15 \mathrm{~km}$ from the main-shock epicenter during period III, and clustering of activity around the main-shock epicenter during period IV. However, for period IV, the concentration of activity toward the main-shock epicenter is more remarkable than in the earlier study; the spread is about $7 \mathrm{~km}$ compared with about $20 \mathrm{~km}$ in the preliminary analysis. This cluster of activity is clearly separated spatially from the activity in the surrounding area. Table 1 lists the events which occurred within $15 \mathrm{~km}$ of the epicenter during period IV.

Brady (1976) investigated the seismicity pattern prior to the San Fernando earthquake to test his inclusion theory of earthquakes. He interpreted the central part of the activity during period II as "the primary inclusion zone of the impending failure". In the present paper we will be primarily concerned with the foreshock activity during period IV rather than the activity during period II.

\section{Wave Form ANALYsis}

All of the five foreshocks were recorded by a Wood-Anderson seismograph at Pasadena $(\Delta \sim 40 \mathrm{~km})$. The response of the Wood-Anderson seismograph is nearly flat over a period range from 0 to $0.6 \mathrm{sec}$, and is suitable for the wave form analysis of these small events. The seismograms of these five events are shown in Figures $2 a$ and $3 \mathrm{a}$. The wave forms recorded on the E-W component (Figure 2a) are very complex yet they are remarkably similar from event to event (see also Figure 6). 
Spatial distribution of relocated epicenters

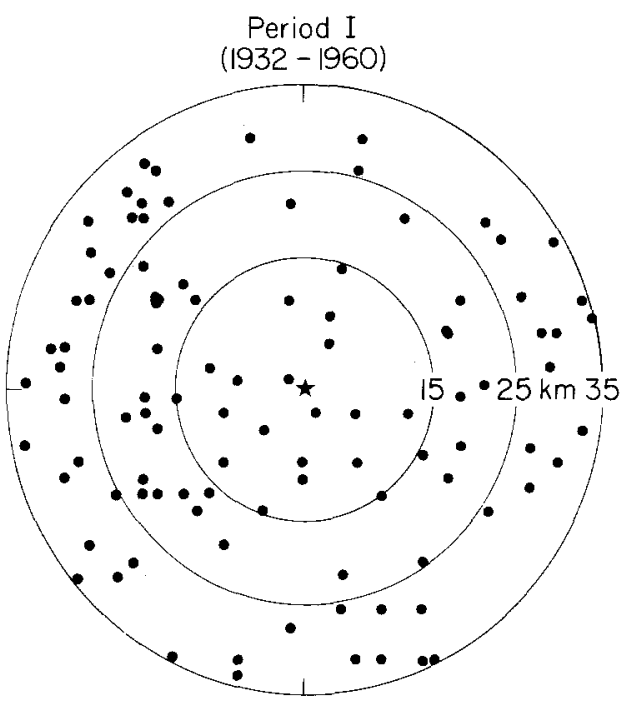

Period III (1965-1968)

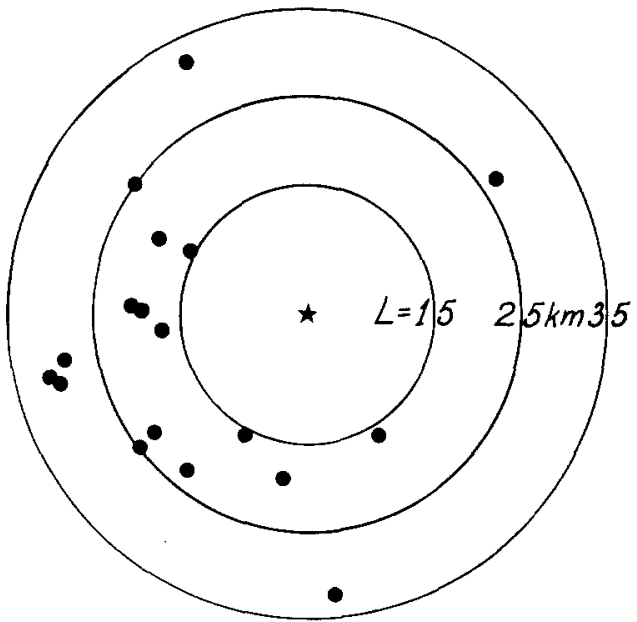

Period II

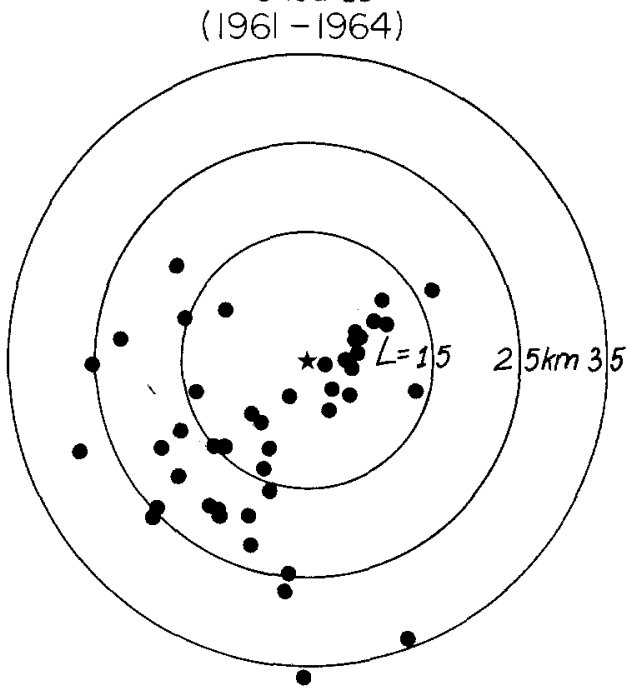

Period IV $(1969-1970)$

* Epicenter of the 1971 San Fernando Earthquake

- Epicenter of the events in the respective period

$L$ Distance from the 1971 San Fernando Earthquake

FIG. 1. Spatial distribution of relocated epicenters for four periods: period I (1932 to 1960), period II (1961 to 1964), period III (1965 to 1968), and period IV (1969 to February 1971). The asterisk is the epicenter of the 1971 San Fernando earthquake $\left(34^{\circ} 25.78^{\prime} \mathrm{N} ; 118^{\circ} 22.02^{\prime} \mathrm{W} ; 12 \mathrm{~km}\right)$. 
The N-S component (Figure 3a) shows less complexity. These seismograms can be compared with those during period II (1961 to 1964) which are shown in Figures $2 b$ and $3 \mathrm{~b}$. The wave forms of all the events with $M_{L}<3$ that occurred within $15 \mathrm{~km}$ from the epicenter are shown. Figure $2 \mathrm{~b}$ (E-W component) clearly shows a greater variation of wave form than Figure 2a, and except for the 9th seismogram from the $t o p$, the wave forms in Figure $2 \mathrm{~b}$ are either impulsive or long period; in general the wave forms of the E-W component seismograms of the foreshocks exhibit far more complexity than those during period II. Also, the foreshocks show consistently short-period oscillations at the beginning of the $S$ phase, while those during period

TABLE I

Foreshocks of the 1971 San Fernando Earthquake

\begin{tabular}{crccc}
\hline Date & Time & Lat ( $\left.{ }^{\circ} \mathrm{N}\right)$ & Long ( $\left.^{\circ} \mathrm{W}\right)$ & $M_{L}$ \\
\hline & (h.m.s.) & & & \\
Apr. 26, 1969 & 2.42 .41 .8 & $3419.9^{\prime}$ & $11824.6^{\prime}$ & 2.8 \\
July 24, 1969 & $\mathbf{1 . 2 7 . 3 0 . 1}$ & $3423.6^{\prime}$ & $11822.4^{\prime}$ & 2.5 \\
Aug. 15, 1969 & 19.50 .54 .4 & $3424.3^{\prime}$ & $11820.1^{\prime}$ & 2.6 \\
Mar. 21, 1970 & 0.41 .02 .4 & $3422.9^{\prime}$ & $11824.1^{\prime}$ & 2.5 \\
Sept. 28, 1970 & 23.12 .02 .6 & $3424.4^{\prime}$ & $11819.8^{\prime}$ & 2.6 \\
\hline
\end{tabular}

II show very variable periods, from a very emergent long period to a relatively short period comparable to the foreshocks. The difference between the events during period II and the foreshocks is not very obvious on the N-S component (Figure 3, a and $b$ ).
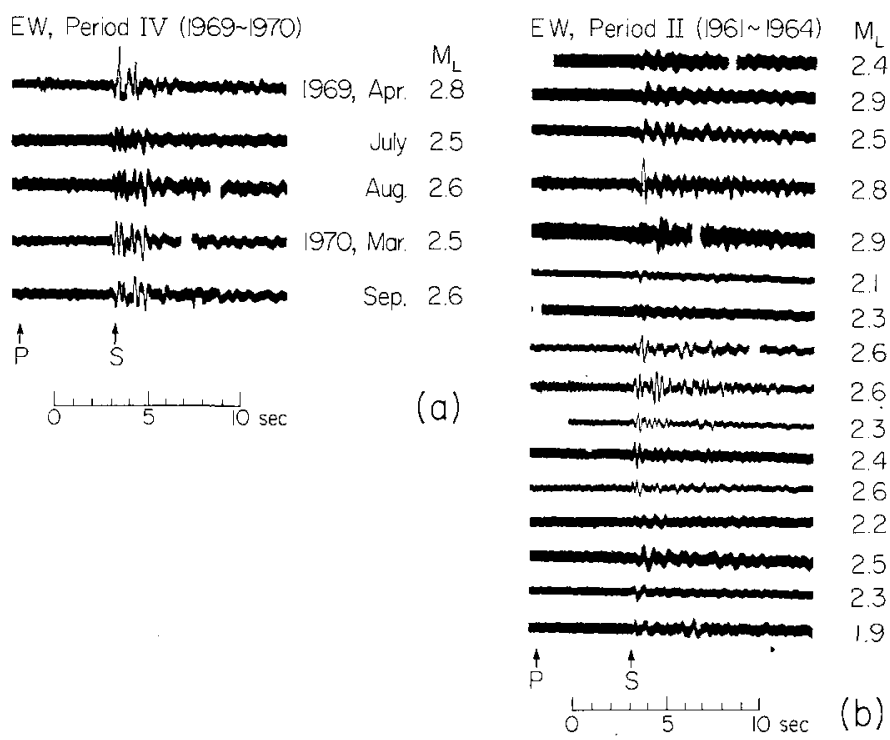

FIG. 2. The E-W component Wood-Anderson seismograms of the events within $15 \mathrm{~km}$ from the epicenter recorded at Pasadena for the period 1969 to 1970 (foreshocks) (a) and 1961 to 1964 (b). Note the complexity of the wave forms of the foreshocks and the similarity between them.

The observation that the wave form of the foreshocks is complicated on the E-W component but is relatively simple on the N-S component suggests that the polarization angle changed during the arrival of the $S$-wave group.

The wave forms of the events which occurred outside the immediate vicinity of 
the main-shock epicenter are relatively simple as shown in Figure 4. None of the events in this figure shows the complexity exhibited by the foreshocks.

From these observations we conclude that the five events which occurred during the 2-year period immediately before the main shock are very distinct from other events which occurred either in the same area prior to this period or in the area outside the immediate vicinity of the epicentral area during the same period.

This complexity could be explained in terms of either a source effect or a propagation effect. However, in view of the similarity of the wave form, the complexity is probably not caused by source dynamics. It is unlikely that a complex source process would produce almost identical wave forms for all events. Thus, the complexity is most likely due to propagation effects. The close similarity of the wave forms strongly suggests that these foreshocks occurred at nearly the same place.

Unfortunately, the number of seismographic stations prior to the San Fernando
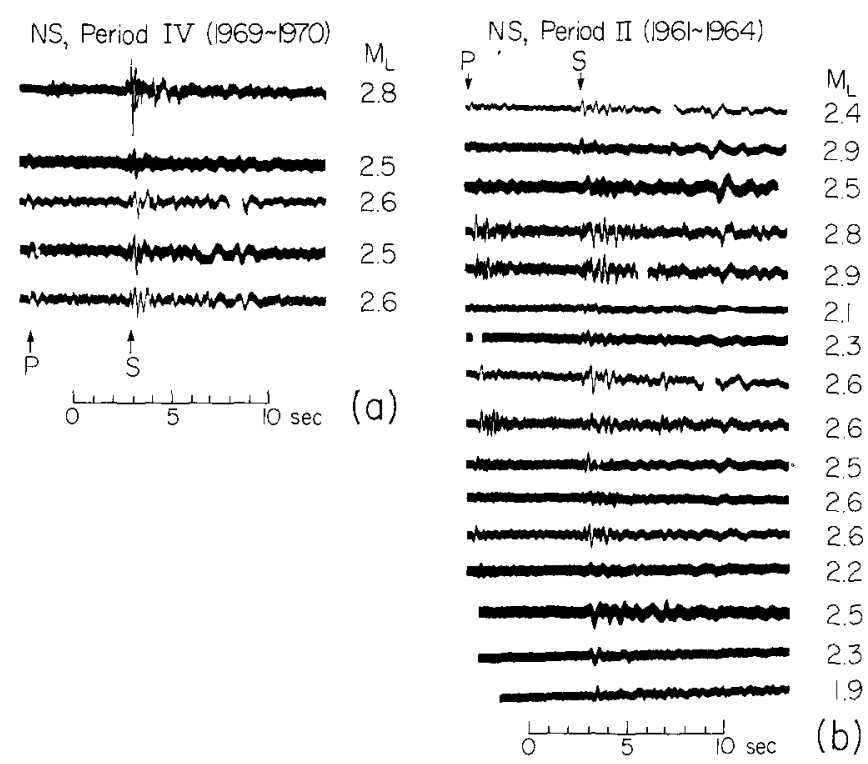

FIG. 3. The N-S component Wood-Anderson seismograms of the events within $15 \mathrm{~km}$ from the epicenter recorded at Pasadena for the period 1969 to 1970 (foreshocks) (a) and 1961 to 1964 (b).

earthquake was not large enough to constrain the depth of these events within several $\mathrm{km}$. However, wave forms of the aftershocks can be used to constrain the depth. The hypocenters of the aftershocks can be constrained very well owing to the substantial increase in the number of local stations after the San Fernando earthquake. We chose aftershocks with $M_{L}<3$ that occurred within $15 \mathrm{~km}$ from the main-shock epicenter. These aftershocks were relocated by using the master-event method. The wave forms of these events recorded at Pasadena are shown in Figure 5 in order of increasing depth. The two aftershocks with a depth of $10 \mathrm{~km}$ have wave forms very similar to that of the foreshocks (see also Figure 6), suggesting that the depth of the foreshocks is also about $10 \mathrm{~km}$. Since the depth of the main shock of the San Fernando earthquake is about 10 to $12 \mathrm{~km}$ (Langston, 1978; Hadley and Kanamori, 1978), we conclude that the foreshocks originated from a very small area in the immediate proximity of the hypocenter of the main shock. Also the event on the 9 th line of Figure $2 \mathrm{~b}$ probably occurred near the hypocenter of the main shock. 


\section{MEChANISM}

Prior to the San Fernando earthquake, the station coverage was not good enough to determine the mechanism of small earthquakes in the San Fernando area. However, the distribution of the $P$-wave first motion at the individual seismographic stations can be used to investigate temporal variations of the mechanism. Figure 7
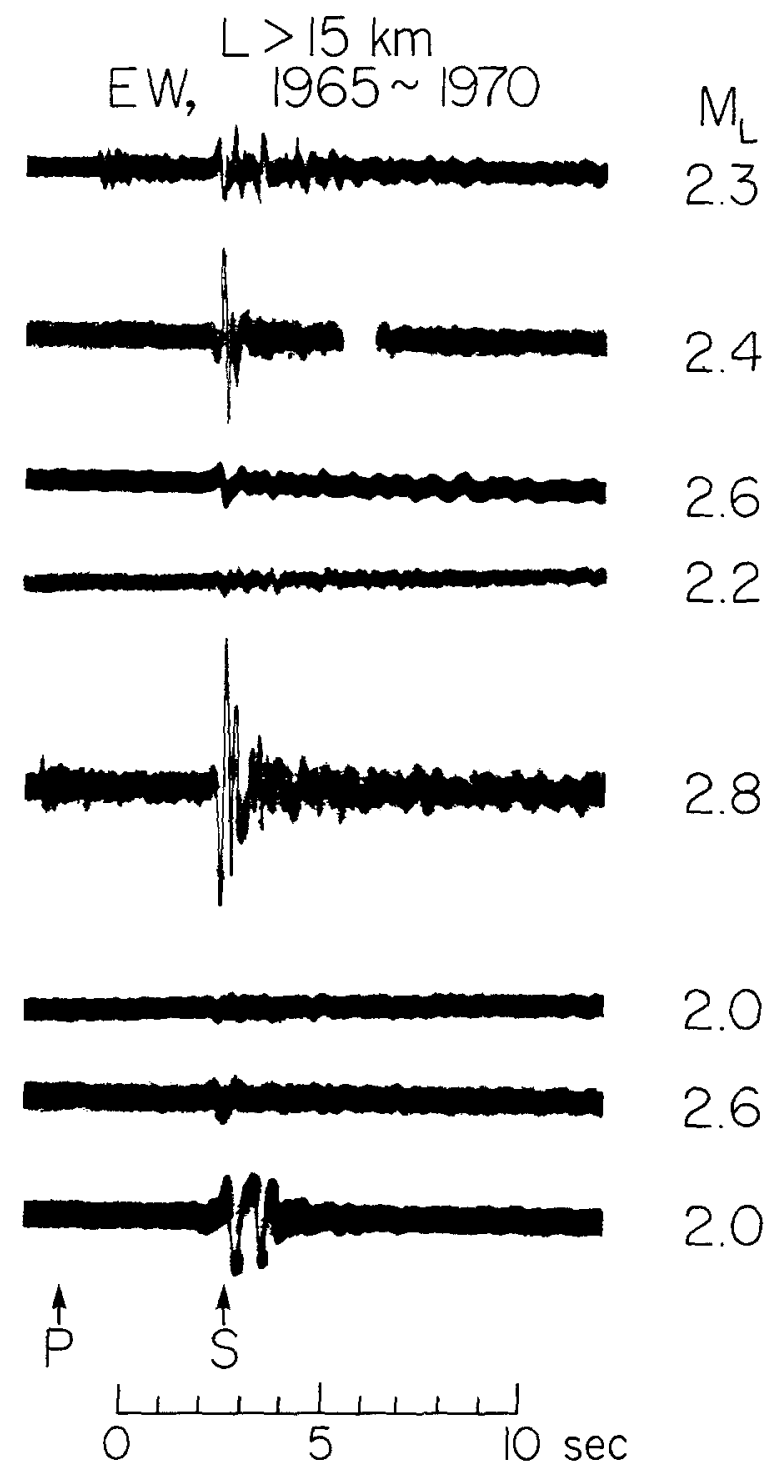

FIG. 4. The E-W component Wood-Anderson seismograms, recorded at Pasadena, of the events which occurred outside a circle of radius $15 \mathrm{~km}$ around the epicenter during the period 1965 to 1970 .

shows the first-motion data for the events which occurred within $15 \mathrm{~km}$ from the epicenter of the San Fernando main shock. The mechanism of the five foreshocks, in particular the last four events of this sequence, is nearly identical. The pattern for these events is very different from that of the aftershocks or the main shock. The earthquakes prior to 1965 show a more random pattern than the events during period IV. 


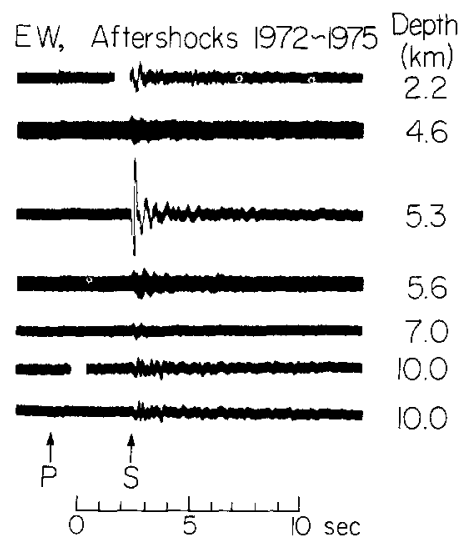

FiG. 5. The E-W component Wood-Anderson seismograms of the aftershocks of the 1971 San Fernando earthquake recorded at Pasadena. Note the similarity between the events at $10 \mathrm{~km}$ depth with those shown in Figure 2a.

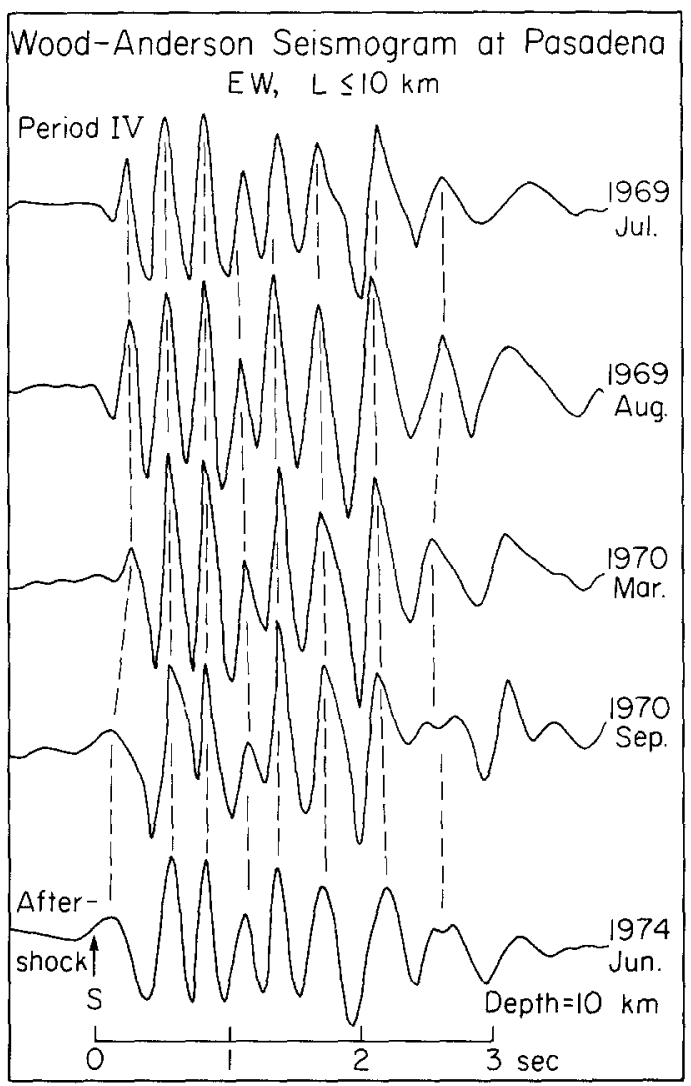

FIG. 6. Comparison of wave forms between four foreshocks and an aftershock at $10 \mathrm{~km}$ depth. 
The polarity of the seismographs of the Caltech stations has been routinely checked by using teleseismic events and explosions. Although polarity check by using teleseismic events is not completely free from ambiguity, consistency of the first motion from station to station within the network can be used to spot stations with polarity reversal. We went through our card file and the result is summarized in the table in the Appendix. As shown in the table, the polarity was correct most of the times. For the aftershocks, the polarity has been carefully checked by Whitcomb (1973). Thus we believe that the pattern shown in Figure 7 represents the real change in the radiation pattern rather than accidental polarity reversals at the stations.

The temporal change in the mechanism during the foreshock sequence or between foreshocks and aftershocks has been reported by several investigators. Sadovsky $e t$ al. (1972) reported a rotation of stress axes before two earthquakes in middle Asia. Engdahl and Kisslinger (1977) found that the principal axes of stress rotated nearly

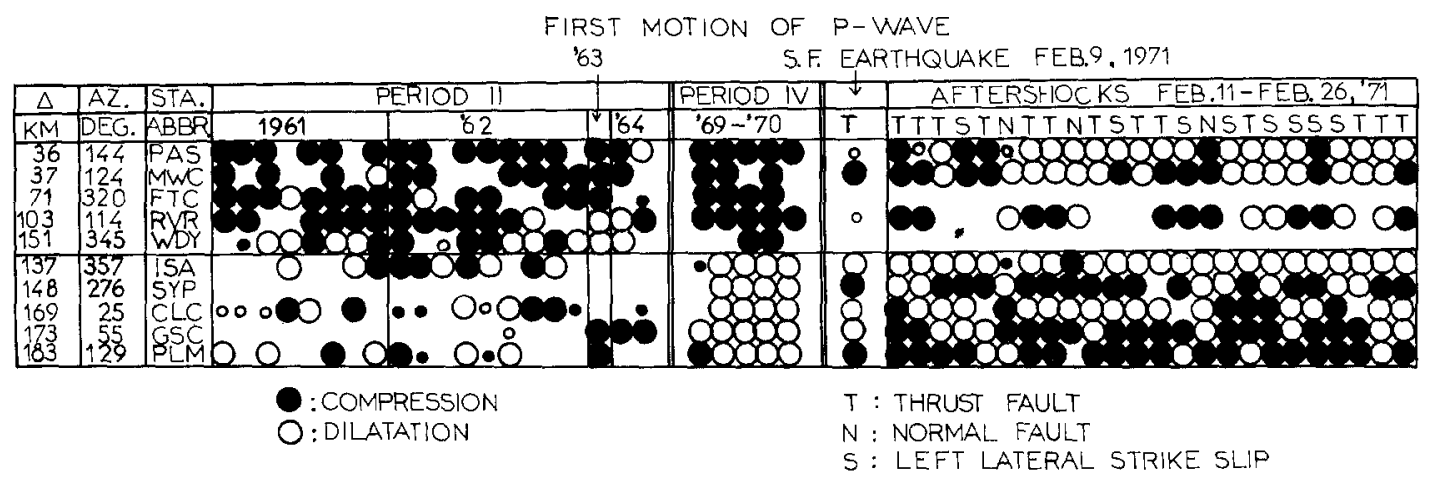

FIg. 7. The P-wave first motion at the individual stations. All the events during period II and period IV and the aftershock sequence that occurred within $15 \mathrm{~km}$ from the epicenter are shown. Note that the pattern for the foreshocks (period IV) is different from that of either the main shock or the aftershocks. Also, the events during period II show more variations in the pattern than the foreshocks. The data for periods II and IV were read by the present authors and those for the main shock and the aftershocks are taken from Whitcomb (1973).

$90^{\circ}$ during a foreshock sequence before a magnitude 5 earthquake in the central Aleutians. More recently, Fuis and Lindh (1978) and Lindh et al. (1978) suggested, on the basis of $P$-to- $S V$ amplitude ratios, that the orientation of the fault planes changed between foreshocks and aftershocks in three California earthquakes, 1975 Galway Lake earthquake, 1975 Oroville earthquake, and 1977 Briones Hills earthquake.

\section{Temporal Variation of the Number of Small Local Events}

Figure 1 includes all the events that were located by the Caltech seismographic network. It is possible that even smaller earthquakes which could not be located by the network occurred in the epicentral area just before the San Fernando earthquake. In order to explore this possibility we examined the short-period (Benioff 1 to 0.2$)$ seismograms at Mt. Wilson $(\Delta \approx 40 \mathrm{~km})$ for the period from January 1970 to February 9, 1971. The number of events whose $S-P$ times are between 3.8 and $6 \mathrm{sec}$ were counted and plotted in Figure 8. The number of events in even intervals of 30 days counting back from the main shock is plotted for the period from November 1970 to February 1971. Prior to September 1970, monthly numbers are plotted. The 
events which were located by the network were not counted. These events are larger than $M_{L}=1.5$. Figure 9 shows examples of the seismograms of these events; seismograms of three aftershocks with a comparable magnitude are shown for comparison. Although a number of events smaller than $M_{L}=1.5$ were recorded, they were often indistinguishable from the noise and were not included in the present analysis. The telemetry of the Mt. Wilson station was started in September 1970, and during the transitional period from September to mid-November 1970, the gain of the seismometer was considerably lower than normal so that the records could not be used for the present analysis. Two stations, Pasadena and Fort Tejon,

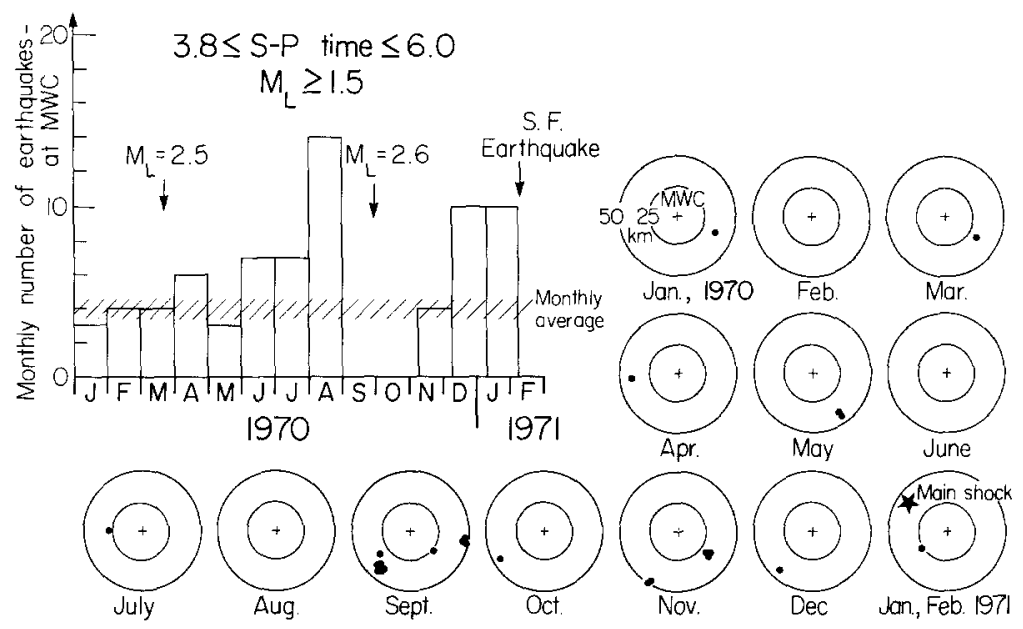

FIG. 8. Monthly number of events with $S-P$ times between 3.8 and $6 \mathrm{sec}$ recorded at Mt. Wilson. Epicenters of events located by the Caltech network (within the same range) during the same period are shown for each month. Note the lack of notable activity during December, January, and February.

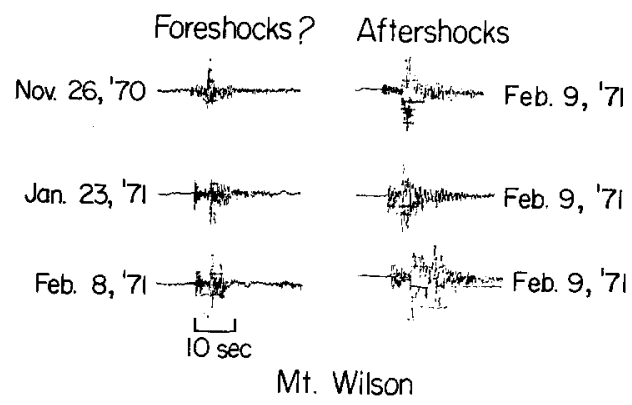

Fig. 9. Examples of seismograms used in Figure 8. Aftershocks with comparable magnitudes are shown for comparison.

are located within $70 \mathrm{~km}$ of the San Fernando epicenter, but the signal-to-noise ratio at these stations was not high enough for the present purpose.

The background activity in this area can be estimated from the magnitudefrequency relation prior to the San Fernando earthquake (K. McNally, personal communication, 1977). For the area between the two concentric circles around Mt. Wilson corresponding to $S-P$ times of 3.8 and $6 \mathrm{sec}$, we estimated that the background activity is about 4 events/month ( $M_{L} \geqq 1.5$ ). As shown in Figure 8 , the monthly average of the number of events prior to June 1970 is approximately equal to this 
estimate. The number of events increased from December 1970 to February 1971 when the monthly number became about 2.5 times larger than the average, suggesting that the number of small earthquakes increased slightly in the epicentral area of the San Fernando earthquake just before the earthquake. Although it is possible that a coincidental swarm activity occurred somewhere else at distances of 25 to $50 \mathrm{~km}$ from the Mt. Wilson station, no obvious swarm activity was identified in this range during the period from December 1970, to February 1971, as shown in Figure 8.

The increase in seismicity in August is followed by an $M_{L}=2.6$ event that occurred in the hypocentral area on September 28,1970 , although whether they are causally related or not is inconclusive.

It is probably reasonable to conclude that no prominent increase in seismicity occurred just before the San Fernando earthquake, though a slight increase is suggested.

\section{Conclusion AND Discussion}

The relocation, detailed wave-form analysis and the mechanism study of the foreshocks of the 1971 San Fernando earthquake strongly suggest that these events originated from a very small area in the immediate proximity of the hypocenter of the main shock. In this regard these foreshocks are very distinct from the background activity prior to 1965 . The events prior to 1965 show more variation in wave form and mechanism. The clustering of foreshocks near the epicenter of the main shock has been reported by several investigators. Mogi (1968) showed examples for four major earthquakes (1930 Izu earthquake, 1960 Chilean earthquake, 1963 Kurile Islands earthquake, 1965 Aleutian Islands earthquake) and interpreted them in the light of laboratory data. Kelleher and Savino (1975) suggested that seismicity prior to large earthquakes such as the 1952 Kamchatka earthquake and the 1964 Alaskan earthquake is frequently higher near the epicenter of the main shock than elsewhere in the rupture zone. The result of McEvilly et al. (1967) for the 1966 Parkfield earthquake indicates that the activity near and to the north of the epicenter had been higher prior to the main shock. McNally (1977) found clusters of small earthquakes in the near-source region of moderate earthquakes in central California 2 to 10 years prior to the main shock. The results of Fuis and Lindh (1977) for the 1977 Galway earthquake also show a tight clustering of foreshocks around the main shock epicenter.

The complexity of the wave form was probably caused by a structural heterogeneity near the source region. Although it is not possible to determine the structure from the present data, one possible model that explains the complexity may be made as follows. Suppose a weak fault zone exists in a geometry as shown by Figure 10. We assume that the shear velocity in the weak zone is 20 per cent lower than in the surrounding zone. Then, a number of rays having different paths arrive at the Pasadena station as shown in Figure 10. Depending upon the geometry of the weak zone, some of the rays are reflected in the weak zone giving rise to later arrivals at the station with a very large amplitude. In the example shown in Figure 10 (Tai-Lin Hong, personal communication, 1977), an isotropic source is assumed and the calculation is made by using geometrical ray theory. As shown in the figure, the second and third arrivals are very large and arrive at the station with time intervals of 0.5 to $1 \mathrm{sec}$ which are adequate to explain the observed complexity.

The complex refractions and reflections as postulated above would cause a change in the polarization angles of $S$ waves which might explain the difference in the 
observed complexity between the E-W and the N-S components. Since the earthquake source is a double couple and the structure may be more complex, the actual situation is somewhat different from this model. In view of the lack of detailed knowledge of the source mechanism and the three-dimensional structure near the hypocentral region, more detailed modeling would not be very meaningful. However, it is encouraging that the simple structural heterogeneity shown in Figure 10 can explain the main feature of the observed wave form.

The fact that the mechanism of the foreshocks is different from the main shock can be interpreted in terms of local stress concentration caused by an asperity near the hypocenter. The local stress field near the asperity may be substantially distorted from the regional tectonic stress field and give rise to a mechanism different from the main shock which represents the regional tectonic stress field.

The observation that the first swing of the $S$-wave train is relatively short period for all the foreshocks is also consistent with this high-stress asperity model. This

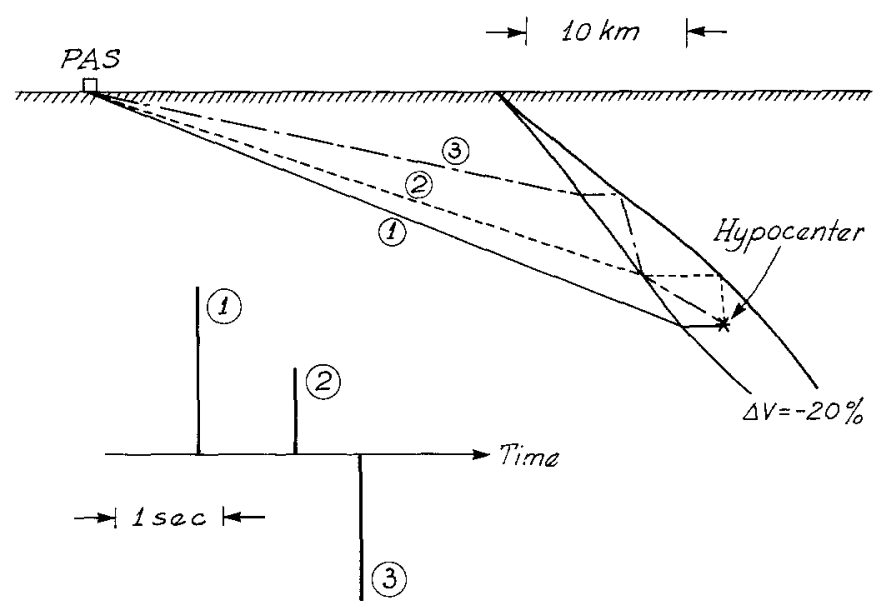

FIG. 10. A model which causes complexity (Tai-Lin Hong, personal communication, 1977). The arrival times of the three rays are shown in the lower left corner.

model suggests that the main shock was also initiated by a high-stress event. Hanks' (1974) suggestion that the San Fernando earthquake was initiated by a very high stress event supports this model.

Brady $(1974,1976,1977)$ postulated that stress concentration in the focal volume should be an essential feature of the earthquake preparatory process. However, details of how and when stress concentration occurs before a large earthquake are presently unknown. The present paper provides seismological evidence for stress concentration before the San Fernando earthquake.

Recently many investigators reported various types of long-term precursory changes of seismicity prior to a large earthquake (e.g., Inouye, 1965; Mogi, 1969; Kelleher and Savino, 1975; Sekiya, 1976, 1977; Engdahl and Kisslinger, 1977; Ohtake, 1976; Ohtake et al., 1977; Evison, 1977). However, the pattern seems to be different from event to event, and it is not clear whether there is a universal precursory seismicity pattern or not. Also, in the previous studies identification of the seismicity pattern is solely based on spatiotemporal distributions of the epicenters and is 
somewhat subjective; the resulting pattern depends upon the area and the time period considered, and the magnitude threshold for the events to be included in the analysis. We emphasize here the importance of studying physical characteristics of the precursory events for better understanding of the physical process leading to an earthquake.

Although the model presented here involves various assumptions and is nonunique, the fact that the events just before the main shock had a distinct wave form is definitive. It is encouraging that we could observationally distinguish unambiguously these events from the background activity. It does not necessarily follow that every foreshock sequence can be identified on this basis. Nevertheless, the present result strongly suggests that detailed analyses of wave forms, spectra, and mechanism can provide a very powerful diagnostic method for identifying a foreshock sequence.

\section{ACKNOWLEDGMENTS}

We wish to thank Tai-Lin Hong for providing us with the results of numerical computation of reflected arrivals. Many helpful and stimulating discussions with Don Anderson, Robert Geller, David Hadley, Karen McNally, Seth Stein, and Gordon Stewart are gratefully acknowledged. Carl Johnson and Christine Powell helped us in retrieval of local seismicity data. Takeshi Mikumo and Kazuaki Nakamura made helpful comments on the manuscript.

Mizuho Ishida was supported by a fellowship from the Science and Technology Agency in Japan. This research was sponsored by U.S. Geological Survey Contracts 14-08-0001-15893, 14-08-0001-16711, and 1408-0001-16776.

\section{REFERENCES}

Brady, B. T. (1974). Theory of earthquakes, I, Pageoph 112, 701-725.

Brady, B. T. (1976). Theory of earthquakes, Pageoph 114, 1031-1082.

Brady, B. T. (1977). Anomalous seismicity prior to rock bursts: Implications for earthquake prediction, Pageoph 115, 357-374.

Engdahl, E. R. and C. Kisslinger (1977). Seismological precursors to a magnitude 5 earthquake in the central Aleutian Islands, J. Phys. Earth (in press).

Evison, F. F. (1977). Fluctuations of seismicity before major earthquakes, Nature 266, 710-712.

Fuis, G. S. and A. G. Lindh (1977). A change in fault-plane orientation between foreshocks and aftershocks of the Galway Lake earthquake, $M_{L}=5.2,1975$, Mojave Desert, California (submitted for publication).

Hadley, D. and H. Kanamori (1978). Recent seismicity in the San Fernando region, and tectonics of the west-central transverse ranges, California, Bull. Seism. Soc. Am. 68, 1449-1457.

Haicheng Earthquake Study Delegation (1977). Prediction of the Haicheng earthquake, EOS 58, $236-272$.

Hanks, T. (1974). The faulting mechanism of the San Fernando earthquake, J. Geophys. Res. 79, 1215-1229.

Hileman, J. A., C. R. Allen, and J. M. Nordquist (1973). Seismicity of the Southern California region, 1 January 1932 to 31 December 1972, 83 pp., Seismological Laboratory, California Institute of Technology, Pasadena.

Inouye, W. (1965). On the seismicity in the epicentral region and its neighborhood before the Niigata earthquake, Kenshin Jiho 29, 139-144 (in Japanese).

Ishida, M. and H. Kanamori (1977). The spatio-temporal variation of seismicity before the 1971 San Fernando earthquake, California, Geophys. Res. Letters 4, 345-346.

Johnson, C. E. and D. M. Hadely (1976). Tectonic implications of the Brawley earthquake swarm, Imperial Valley, California, Bull. Seism. Soc. Am. 66, 1133-1144.

Jones, L. and P. Molnar (1976). Frequency of foreshocks, Nature 262, 677-679.

Kelleher, J. and J. Savino (1975). Distribution of seismicity before large strike-slip and thrust-type earthquakes, J. Geophys. Res. 80, 260-271.

Langston, C. A. (1978). The February 9, 1971, San Fernando earthquake: A study of source finiteness in teleseismic body waves, Bull. Seism. Soc. Am. 68, 1-29.

Lee, W. H. K. and J. C. Lahr (1975). HYPO71 (Revised): A computer program for determining hypocenter, magnitude and first motion pattern of local earthquakes, U.S. Geol. Surv. Open File Rept., Washington, D.C., 113 pp. 
Lindh, A., G. Fuis, and C. Mantis (1977). Foreshock amplitudes and fault plane changes: An earthquake precursor? (submitted for publication).

McEvilly, T., W. Bakun, and K. Casady (1967). The Parkfield, California earthquake of 1966, Bull. Seism. Soc. Am. 57, 1221-1244.

McNally, K. C. (1977). Patterns of earthquake clustering preceding moderate earthquakes, central California (submitted for publication).

Mogi, K. (1968). Source locations of elastic shocks in the fracturing process in rocks (1), Bull. Earthquake Res. Inst., Tokyo Univ. 46, 1103-1125.

Mogi, K. (1969). Some features of recent seismic activity in and near Japan (2), Activity before and after great earthquakes, Bull. Earthquake Res. Inst., Tokyo Univ. 47, 395-417.

Ohtake, M. (1976). Search for precursors of the 1974 Izu-Hanto-Oki earthquake, Japan, Pure Appl. Geophys. 114, 1083-1093.

Ohtake, M., T. Matumoto, and G. V. Latham (1977). Seismicity gap near Oaxaca, Southern Mexico as a probable precursor to a large earthquake, Pageoph 115, 375-385.

Sadovsky, M. A., I. L. Nersesov, S. K. Nigmatullaov, L. A. Latynina, A. A. Lukk, A. N. Semenov, I. G. Simbireva, and V. I. Ulomov (1972). The processes preceding strong earthquakes in some regions of middle Asia, Tectonophysics 14, 295-307.

Sekiya, H. (1976). The seismicity preceding earthquakes and its significance to earthquake prediction, Zisin 29, 299-311 (in Japanese).

Sekiya, H. (1977). Anomalous seismic activity and earthquake prediction, J. Phys. Earth (in press).

Whitcomb, J. H. (1973). The 1971 San Fernando earthquake series focal mechanisms and tectonics, Part II of Ph.D. Thesis, California Institute of Technology.

SEISMOLOGICAL LABORATORY

Division of Geological and Planetary Sciences

California Institu'te of Technology

Pasadena, California 91125

Contribution No. 3011

Manuscript received January 23, 1978 


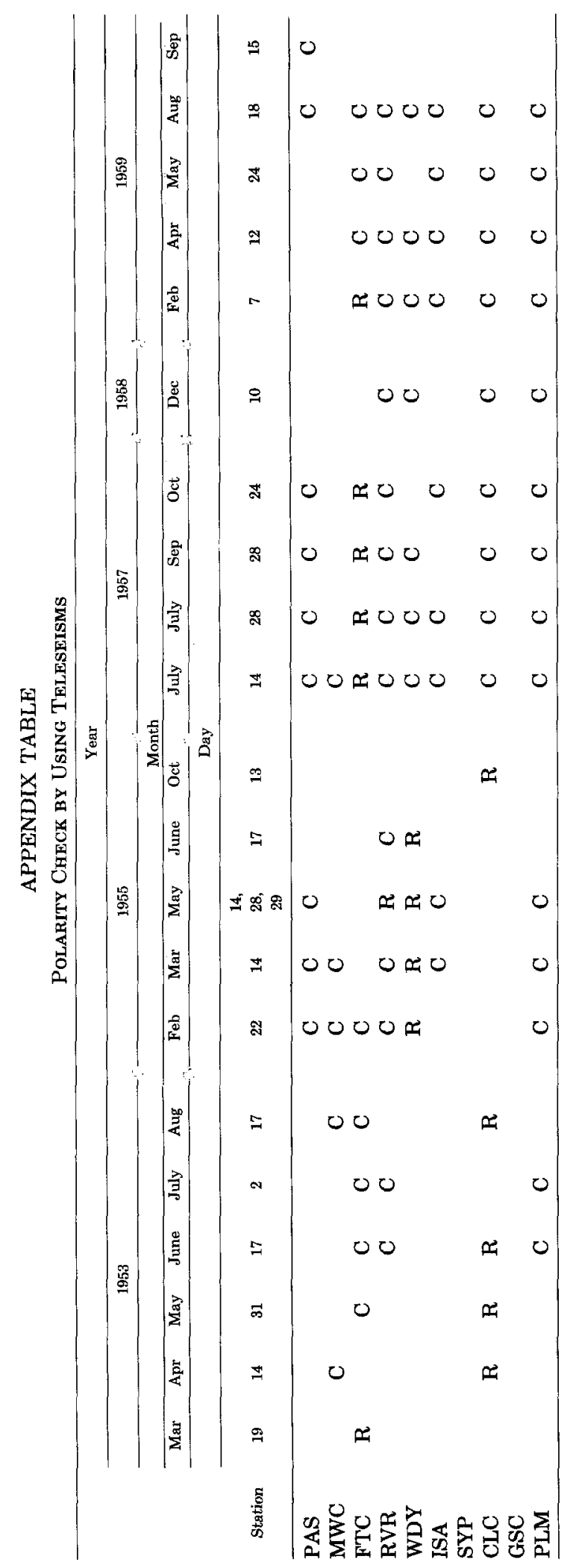




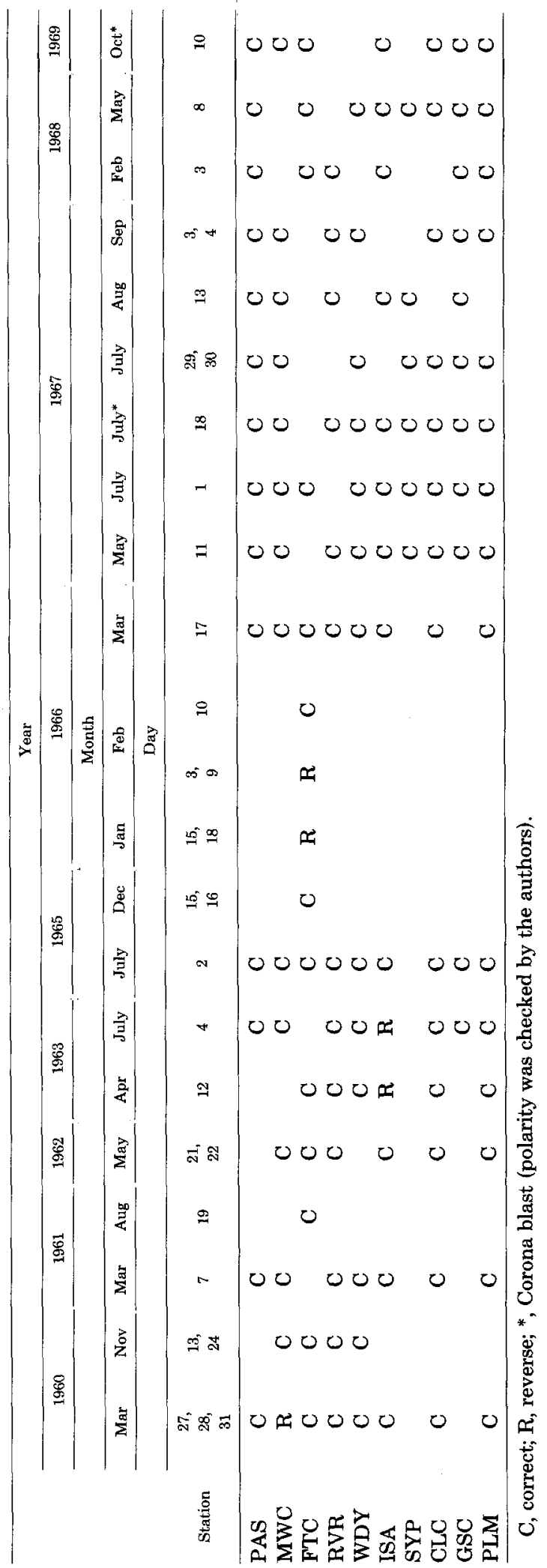

